\title{
مقبرة رقم 58
}

\section{ليلى عزام}

استاذ الآثار والحضارة كلية الآداب جامعة حلوان

\section{مستخلص:}

هذا البحث هو عبارة عن تقريراً مبدئياً عن المقبرة رقم TT 58 فى جبانة الثيخ عبدالقرنة بالأقصر . فى 202017127 حصلت الباحثة على موافقة اللجنة الدائمة للآثار لدراسة ونشر المقبرة. تقع هذه المقبرة فى جبانة الثيخ عبد القرنة وهى لأحد كبار الموظفيين من عصر الأسرة الثامنة عشر و تم اعادة استخدامها واغتصبها فى عصر الرعامسة من قبل كل من:

$$
\text { • • أمنحوتب من عصر الأسرة التاسعة عشر إمر إينت عصر الأسرة العشرين }
$$

المقبرة تتكون من: فناء وصالة عرضية وصالة طولية ونيشة وحجرة جانبية تحتوى البئر المؤدى إلي غرفة البنة

$$
\begin{aligned}
& \text { الكلمات المفتاحية: } \\
& \text { • مقابر الافراد فى طيبة. } \\
& \text { • الثيخ عبد القرنة } \\
& \text { • أمنحوتب } \\
& \text { • أمون إم إينت } \\
& \text { • عصر الرعامسة إلما }
\end{aligned}
$$




\title{
Abstract:
}

\author{
Tomb no. TT 58 \\ By \\ L.M. Azzam
}

This paper is a preliminary report on the unpublished Theban tomb no.58. In 27/7/ 2020 the author of this article was granted the consent of the permanent committee of Ancient Egyptian Antiquities for studying and publishing TT 58. The tomb is located in the necropolis of Sheikh Abd el Qurna. It belongs to an unknown high official of the $18^{\text {th }}$ dynasty and was usurped later on in the Ramesside period by two persons:

- Amenhotep probably from the $19^{\text {th }}$ dynasty.

- Amenemonet from the $20^{\text {th }}$ dynasty.

The tomb consists of: courtyard, transverse hall, longitudinal hall, a niche and a side chamber that comprises the shaft that leads to the burial chamber.

Key word:

- Private Theban tombs.

- Sheikh Abd el Qurna.

- Amenhotep.

- Amenemonet.

- Ramesside period. 


\section{مقبرة رقم 58}

\section{ليلى عزام}

استاذ الآثار والحضارة كلية الآداب جامعة حلوان

تمهيد: يعد الهدف الرئيس من هذه البحث أن تكون نشراً مبدئياً للمقبرة TT58 التى لم تنشر من قبل. والبحث سوف يناول دراسة موقع وتخطيط ومناظر ونصوص المقبرة. وسوف نتبع فى هذا البحث المنهج الوصفى

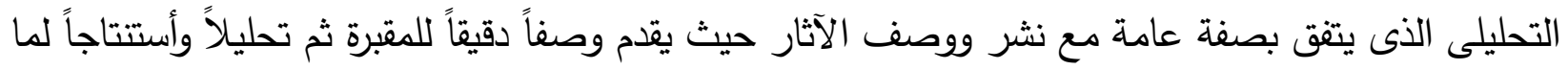
يعكسه المنظر او النص الموضح. وقد تبين أن هذه المقبرة تعود الى عصر الأسرة الثامنة عشر وبالتحديد إلي

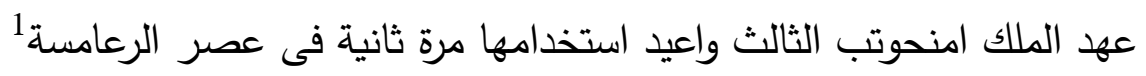

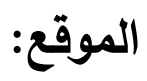

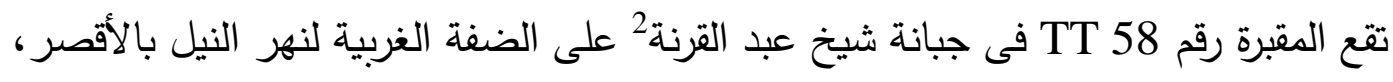

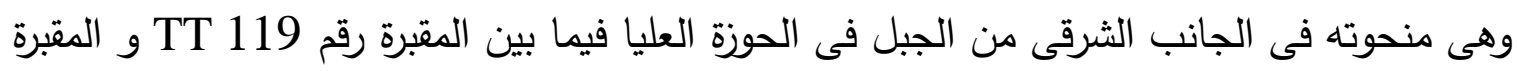

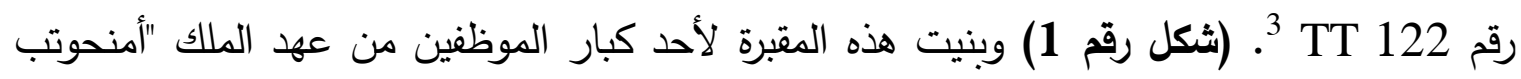
الثالث" غير معروف اسمه حاليًا، وتم إعادة استخدام المقبرة فى عصر الرعامسة من قبل المدعو لهاري

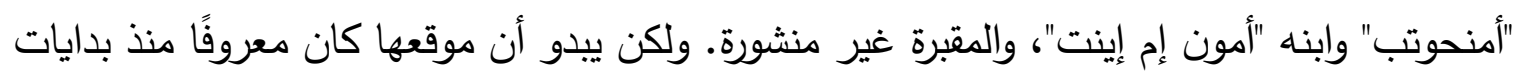

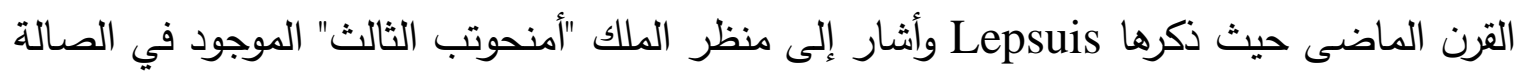
العرضية، كما ذكر أن اسم صاحب المقبرة الأول منذ عصر الرعامسة هو "أمنحوتب" أما اسم صاحبها

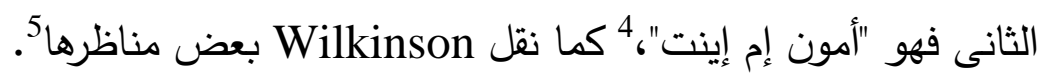

1 حصلت أ.د ليلى عزام على موافقة اللجنة الدائمة للآثار علي نشر وتصوير المقبرة بتاريخ 202017\27. ويعتبر هذا الدقال هو تقريرمبدئى عن المقبرة محل الدراسة. 2 تقع جبانة شيخ عبد القرنة فيما بين منطقة العساسيف شمالاً ودير المدينة جنوبًا، وتضم هذه الجبانة مقابر منحوتة فى صخر الجبل من الأسرة الحادية عشر وحتى الأسرة العشرين، وسميت الجبانة بهذا الاسم نسبة إلى ضريح الثيخ عبد القرنة المبند الموجود بها. (Arnold, 2003, p. 194).

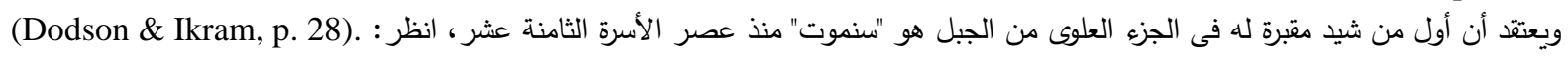

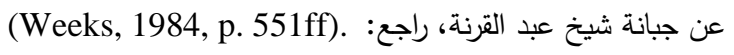

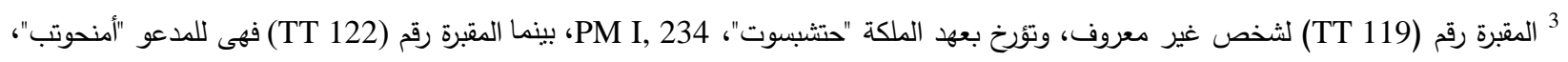

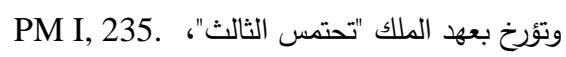
(Lepsuis, pp. 258-43). ${ }^{4}$ PM I, 119. 5 
• لم ترد ألقاب صاحب المقبرة الأصلى أو بمعنى آخر أزيلت ألقابه، ويشير موقعها فى الجزء العلوى من

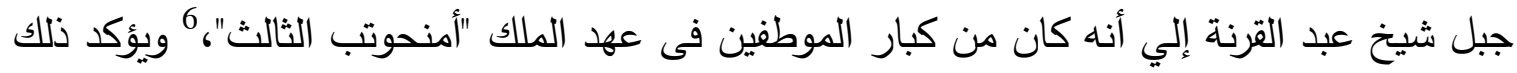
أيضًا تصوير الملك سالف الذكر مرتين علي جانبي مدخل الجدار الثمالي للصالة العرضية بالمقبرة.

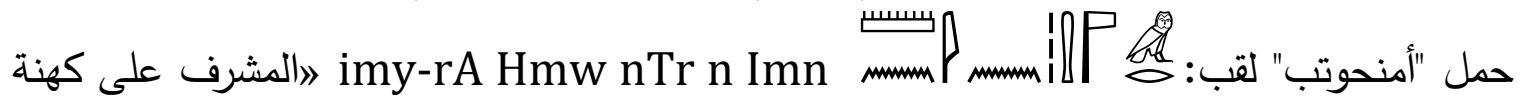

$$
\text { المعبود أمونه. }
$$

• حمل "أمون إم إينت" الألقاب التالية: sS n Hwt-nTr n Ra-mss- المعبود أمونه، ${ }^{8}$ mry- imn, mry mi Imn

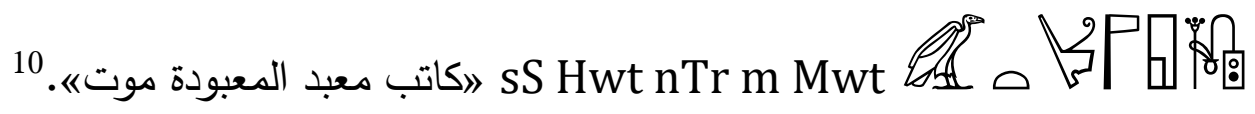
تخطيط المقبرة: - ت

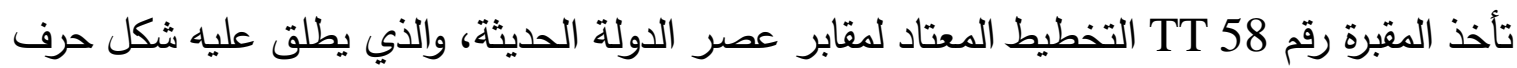

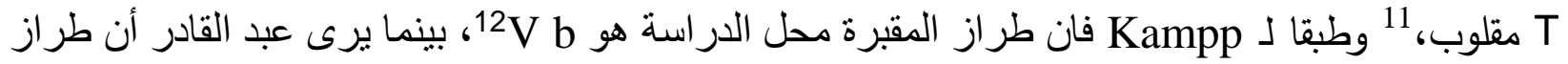

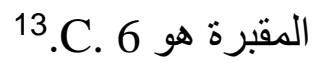
• الفناء: تتكون المقبرة من فناء مفتوح يبلغ طوله حوالى 11 متر، هذا الفناء كان يحده سورين جانبيين

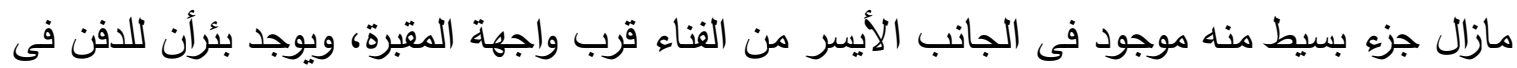
الطرفين الأيمن والأيسر من الفناء. يثغل الجانب الثمالى من الفناء واجهة المقبرة جزء من جانبها

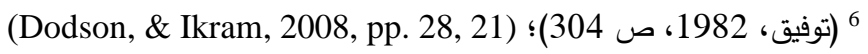
7 ذكر هذا اللقب جاردنر فى كتابه الصادر عام 1913 راجع: (Gardiner, \& Weigall, 1913, p. 20) وأشار البعض ان هذا اللقب غير موجود

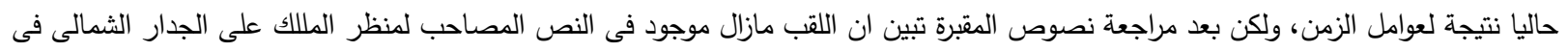

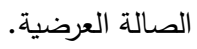
8 8 لقب SS Htpw nTr معروف منذ عصر الدولتين القديمة والوسطى، انظر : (Jones, 2000, p. 864 no. 3160; Ward, 1982, p. 162, no. 1407). بينما اللقب الموجود لدينا الذى يتكون من n + sS Htpw nTr اسم معبود فلم يظهر إلا منذ عصر الدولة الحديثة: (Al-Ayedi, 2006, p. 568, no. 1902).

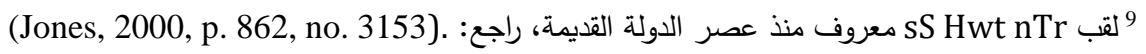
واستمر اللقب حتى عصر الدولة الحديثة: . AEO. I, p. 58) (Al-Ayedi, 2006, p. 575, no. 1870). ${ }^{10}$ (Manniche, 1988, p. 32). ${ }^{11}$ (Kampp, 1996, p. 269). ${ }^{12}$ (Abdul-Qader, 1966, Pl.81). ${ }^{13}$ 
الأيمن متصدع، بينما يوجد في الجانب الأيسر من الواجهة جزء غائر يعتقد أنه كان يمثل نيشة قليلة

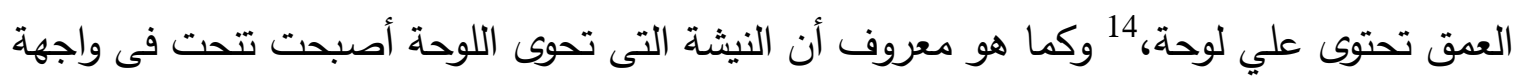
المقبرة فى عصر الرعامسة، وبالتالى يعتقد أن تكون هذه النيشة أضيفت من قبل مستخدم المقبرة فى لئي عصر الرعامسة. 15 (شكل رقم 2) يتوسط المدخل واجهة المقبرة ويبلغ عرضه 1 متر (شكل رقم 3 (A-B الصالة العرضية: يؤدى مدخل المقبرة إلي الصالة العرضية إذ يبلغ طولها 8 متر وعرضها 2 متر، الركال

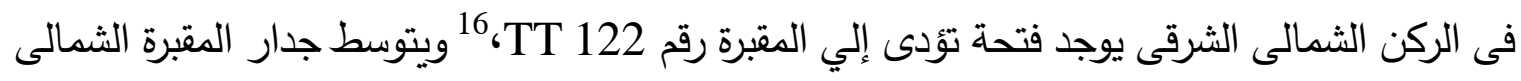

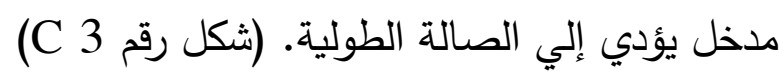

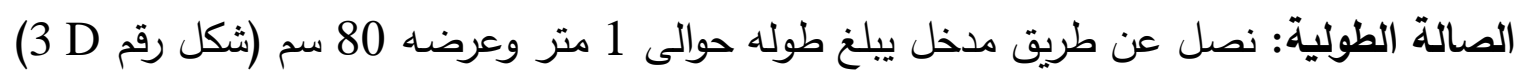

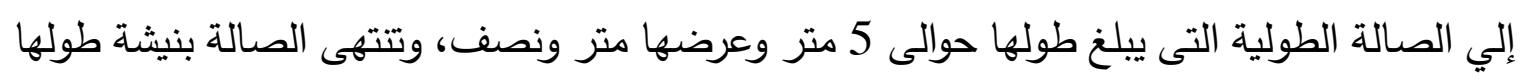
حوالى 1 متر وعرضها 80 سم. (شكل رقم E-F 3 3). • الحجرة الجانبية: يوجد فى منتصف الجدار الغربى للصالة الطولية تقريبًا المدخل المؤدي إلي الحجرة

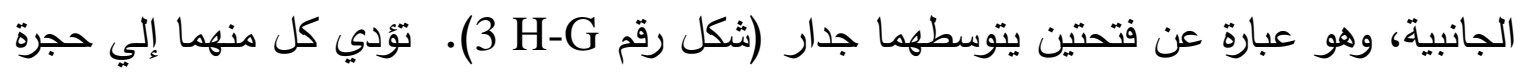

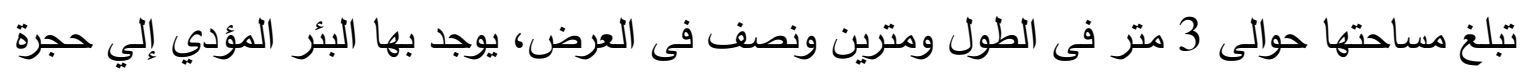

$$
\text { الدفن (شكل رقم 3 I). }
$$

المناظر : - (إ)

نفذت مناظر المقبرة بالرسم علي أرضية صفراء اللون وملونة، واغلب مناظر المقبرة مهشمه وفى حالة

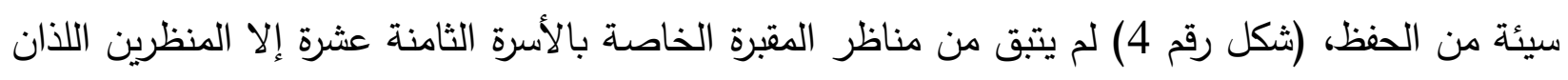

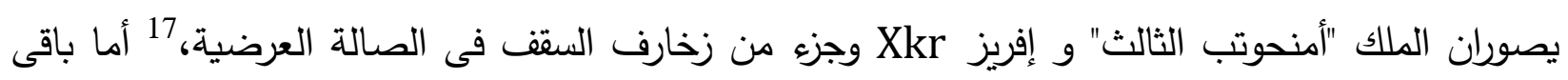
المناظر فترجع إلي عصر الرعامسة. • مناظر الصالة العرضية: 1. الجدار الجنوبي: يقسم مدخل المقبرة هذا الجدار إلى جانبين، حيث صور علي الجانب الأيسر منظر فى ثلاث صفوف، الصف العلوي يحتوى على مناظر من كتاب البوابات، بينما يحتوى 
الصفين الأوسط والسفلى على مناظر تقدمة القرابين. كما صور علي الجانب الأيمن للجدار الجنوبى مناظر ونصوص خاصة بالفصل السابع عشر من كتاب الموتى.

2. الجدار الثرقى: صور علي هذا الجدار تكملة للفصل السابع عشر من كتاب الموتى، ومنظر

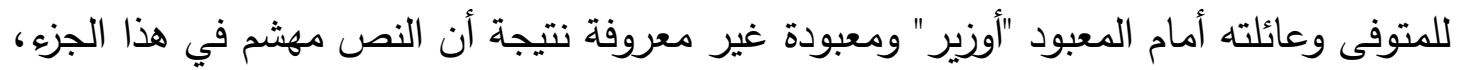
كما صور المتوفى أمام مقصورة، وجزء من نص الفصل 125 من كتاب الموتى، ثم كاهن يقوم بالتبخير أمام رمز "أوزير". 3. الجدار الغربى: يشغل هذا الجدار مناظر من كتاب البوابات ومنظر وزن القلب ومنظر تقديم القرابين ومنظر عازف الهارب ومناظر الجنازة. 4. الجدار الثمالى: يتوسط هذا الجدار مدخل نفضي منه إلي الصالة الطولية، وصور علي جانبى المدخل الملك "أمنحوتب الثالث" جالس داخل جوسق، وصور خلف الملك "أمنحوتب الثالث" الجالس على الجانب الأيسر المعبودة "حتحور"، وأمامه كاهن يرتدى جلد الفهد وشخص وصنص واقف قد

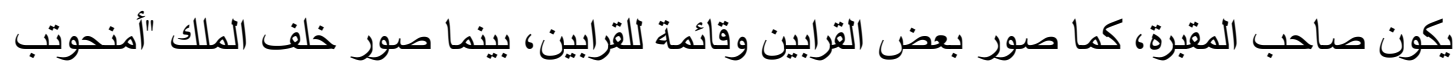
الثالث" الجالس علي الجانب الأيمن المعبودة "ماعت"، وامامه صاحب المقبرة وزوجته، كما صور أسفل الجوسق بعض السوريين المنبطين على الأرض في خضوع وإذلال. 5. السقف: تم زخرفة سقف الصالة الطولية بأشكال هندسية وزهور .

مناظر المدخل المؤدي إلى الصالة الطولية: صور علي جانب الأيمن من المدخل منظر يمثل المتوفى أمام المعبود "أوزير"، بينما صور

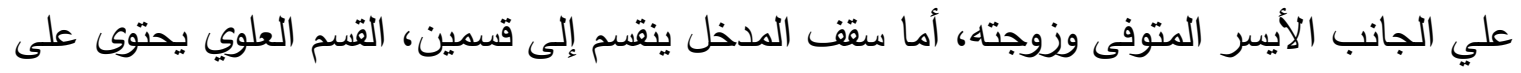

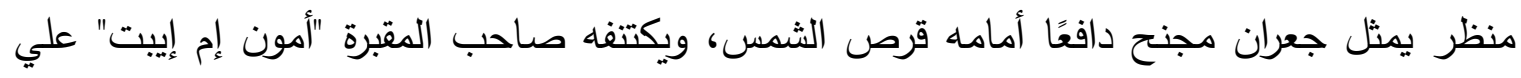

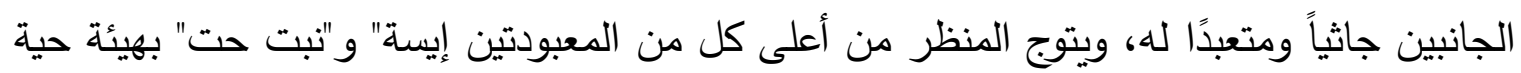
الكوبرا. بينما القسم السفلى يحتوى على منظر لصاحب المقبرة المدعو "أمون إم إيبت" على الجنانين إنبين

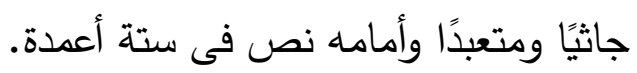

• مناظر الصالة الطولية: 1. الجدار الحنوبى الثرقي: ينقسم إلى ثلاثة صفوف، يحتوى كل منهم على منظر يمثل رجل يقدم

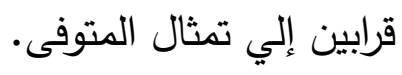


2. الجدار الغربى: ينقسم إلى ثلاث صفوف، يحتوى الصف العلوى على منظر يصور المتوفى وزوجته

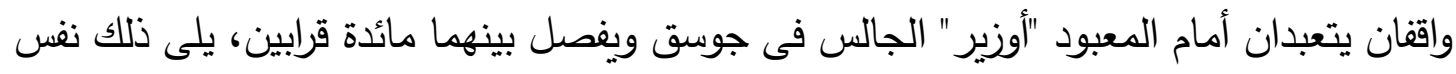

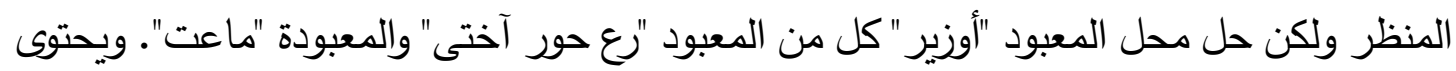

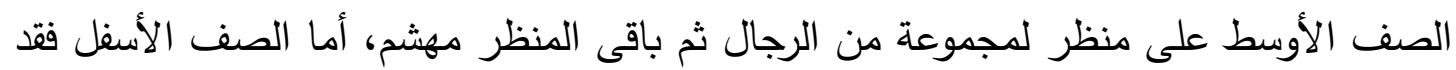

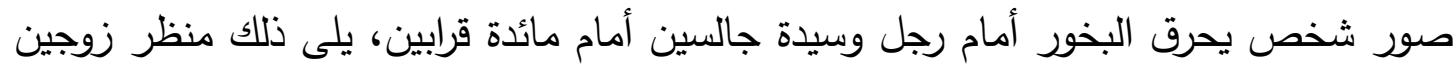
جاثيين أمام المعبودة الثجرة. نجد بعد ذلك المدخل المؤدي إلي الحجرة الجانبية الذي يتوسطه جدار (شكل رقم I I) صور علي هذا الجدار فى صفين مجموعة من السيدات والرجال، ثم تم تكملة المنظر بعد الفتحة الثانية المؤدية إلي الحجرة الجانبية حيث نجد فى الصف العلوى المتوفى وزوجتة واقفان أمام المعبود "أوزير" الجالس داخل جوسق وخلفه تقف معبودة غير معروفة، بينما صور فى الصف الأسفل

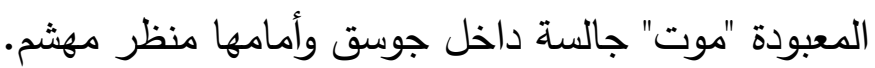

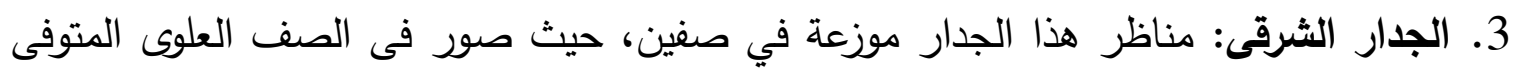

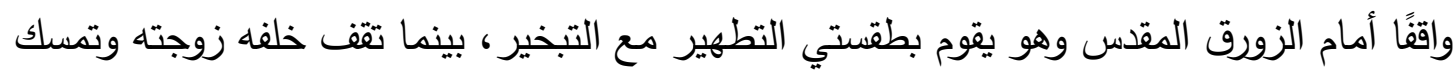
في يدها اليسرى المصلصلة "SSSt" وفى يدها اليمنى باقة لوتس، ويقف فى الزورق المقدس كل

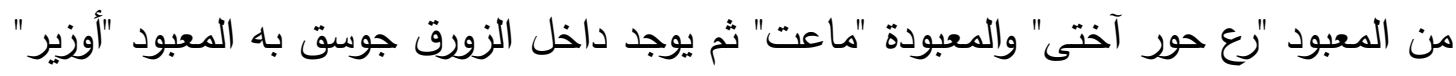

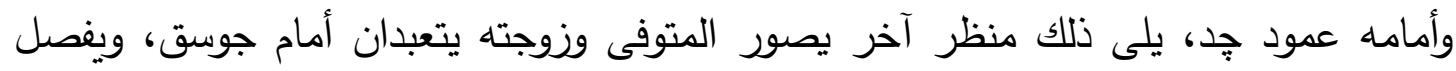

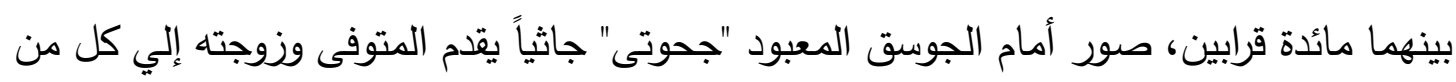

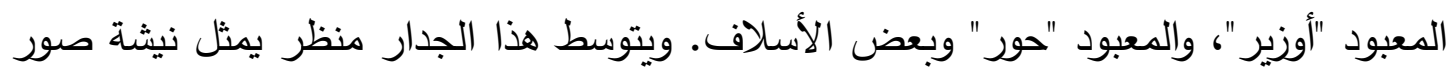

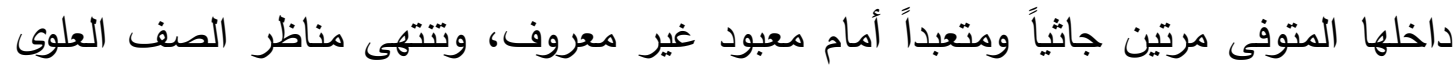

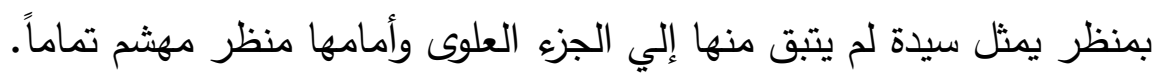
يبدأ الصف السفلى بمنظر يصور كاهن يحرق البخور ويسكب الماء ويقدم القرابين إلي المتوفى لئى وزوجته الجالسين أمام مائدة قرابين، وباقى المناظر حاليًا مهشمه تماماً.

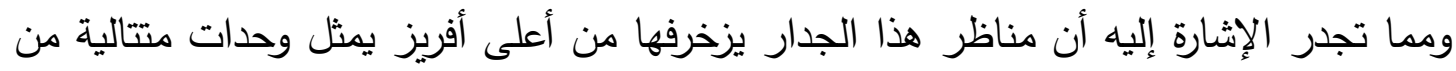
رأس المعبودة "حتحور" ثم علامة "Xkr" ثم "ابن آوى". 4. الجدار الثمالى: يوجد في هذا الجدار النيشة الخاصة بالمقبرة، ويكتنف النيشة مناظر في ثلاثة الثة صفوف، حيث يحتوى الصف الأول علي الجانبين منظر مماثل يصور المتوفى واقفاً بحجم كبير

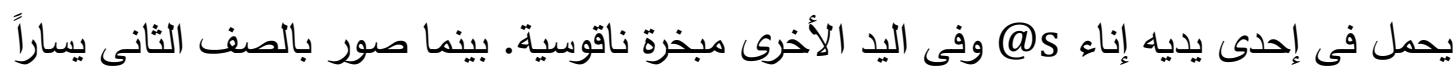


منظر يمثل المتوفى بحجم صغير واقفًا متعبدًا أمام المعبود "إنبو" الجالس داخل جوسق. ويحتوى

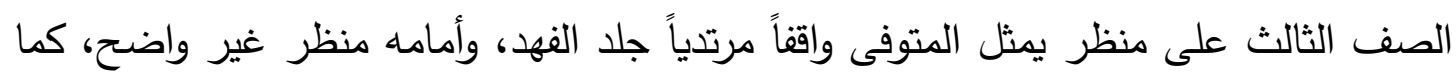

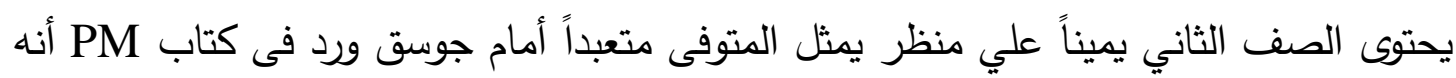
كان يحتوى علي عمود الـ Dd وهو غير واضح تماماً حالياً، 18 بينما منظر الصف الثف الثالث يميناً غير واضح.

أما المناظر المصورة داخل النيشة فقد تم توزعها كالتالى: صور علي الجدار الخلفي والجدارين الجانبيين للمقصورة منظر مزدوج، حيث صور علي الجانب الأيسر المتوفى متجه إلي الداخل

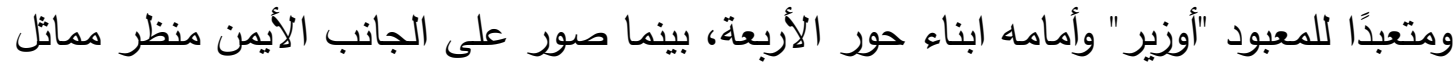

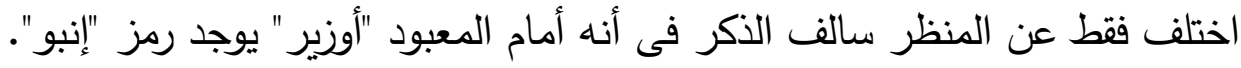
5. السقف: يزين سقف الصالة الطولية مناظر دينية تصور مركب الثمس ويكتنفها المتوفى واقفاً

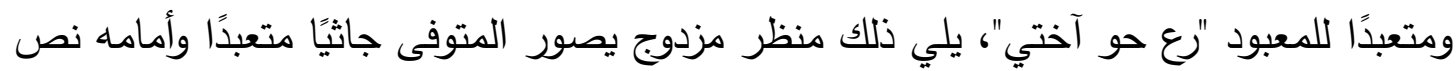
هيروغليفى فى سبعة أعمدة، ثم بعض الأثكال هندسية. 


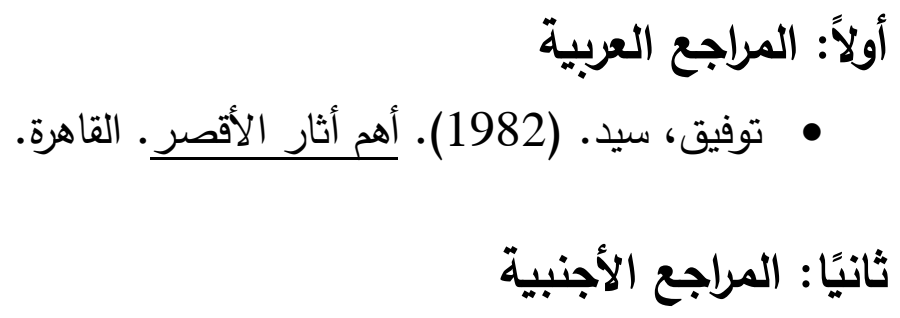

- Abdul-Qader, M. (1966). The Development of the Funerary Beliefs and Practices Displayed in the Private Tombs of the New Kingdom at Thebes. Cairo

- Al-Ayedi, R. (2006). Index of Egyptian Administrative, Religious and Military Titles in the New Kingdom. Ismailia. Cairo.

- Arnold, D. (2003). The Encyclopedia of Ancient Egyptian Architecture. AUC Press. Cairo.

- Dodson, A. \& Ikram, S. (2008). The Tomb in Ancient Egypt, AUC press. Cairo.

- Gardiner, A. \& Weigall, A. (1913). A Topographical Catalogue of the Private Tombs of Thebes, London.

- Jones, D. (2000) An Index of Ancient Egyptian Titles, Epithets and Phrases of the Old Kingdom. BAR International Series 866. Oxford.

- Kampp, F. (1996). Die Thebanische Nekropole: Zum Wandel des Grabgedankens von der XVIII. bis zur XX. Dynastie. Mainz am Rhein.

- Kampp, F. (1998) Overcoming Death - The Private Tombs of Thebes, In Schulz, R., \& Seidel, M., Egypt the World of the Pharaohs. Germany.

- Lepsuis, R., (1975). Denkmäler aus Aegypten und Aethiopien (Text), III. Genéve.

- Manniche, L. (1988). Lost Tombs: A Study of Certain Eighteenth Dynasty Monuments in the Theban Necropolis. London.

- Polz, D. (1990). "Bemerkungen zur Grabbnutzung in der Thebanishcen Nekropole". MDAIK 46.

- Ward, W.A. (1982). Index of Egyptian Administrative and Religious Titles of the Middle Kingdom. Beirut.

- Weeks, K. (1984) "Scheich Abd-el-Qurna” Lä. V, Wiesbaden. 


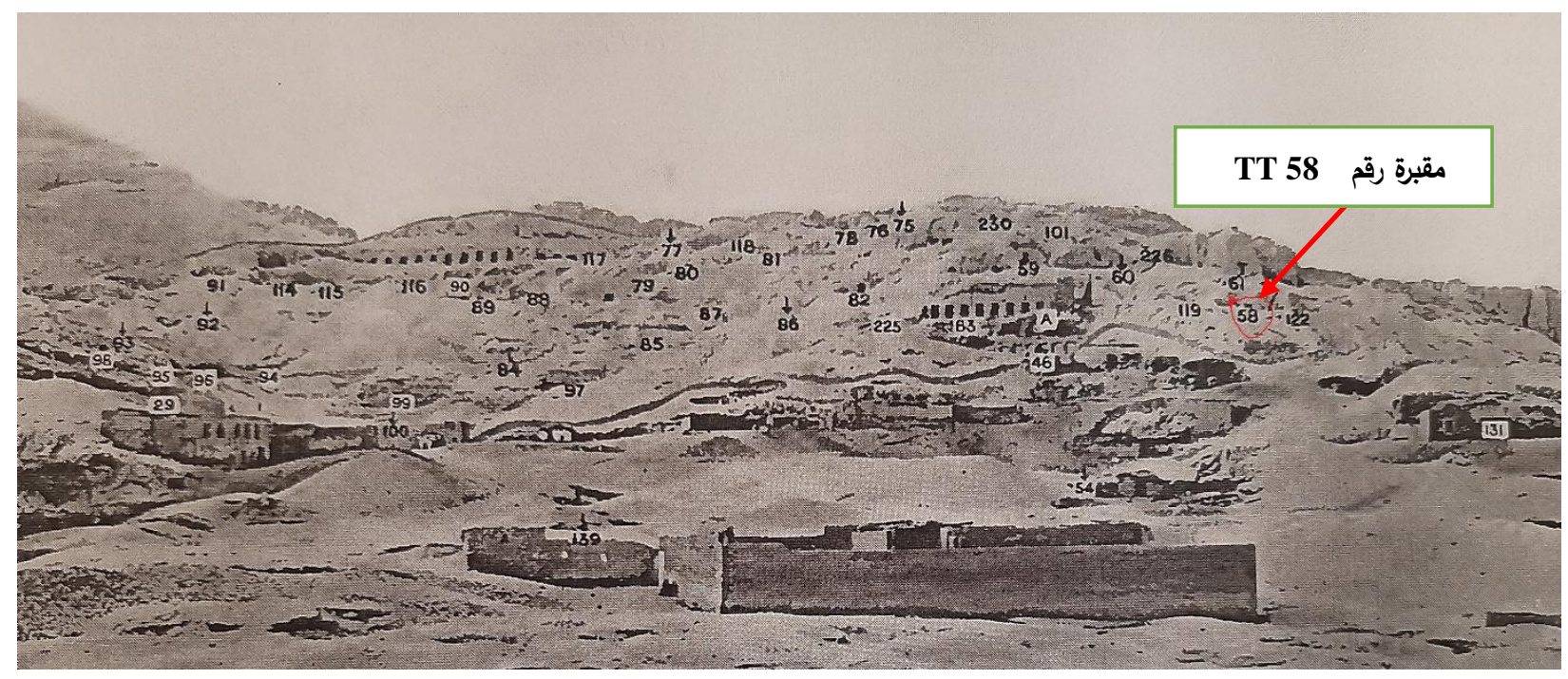

شكل رقم1: موقع المقبرة رقم 58 TT

نقاً عن: . Gardiner, A. \& Weigall, A. Private Tombs of Thebes, Pl. III

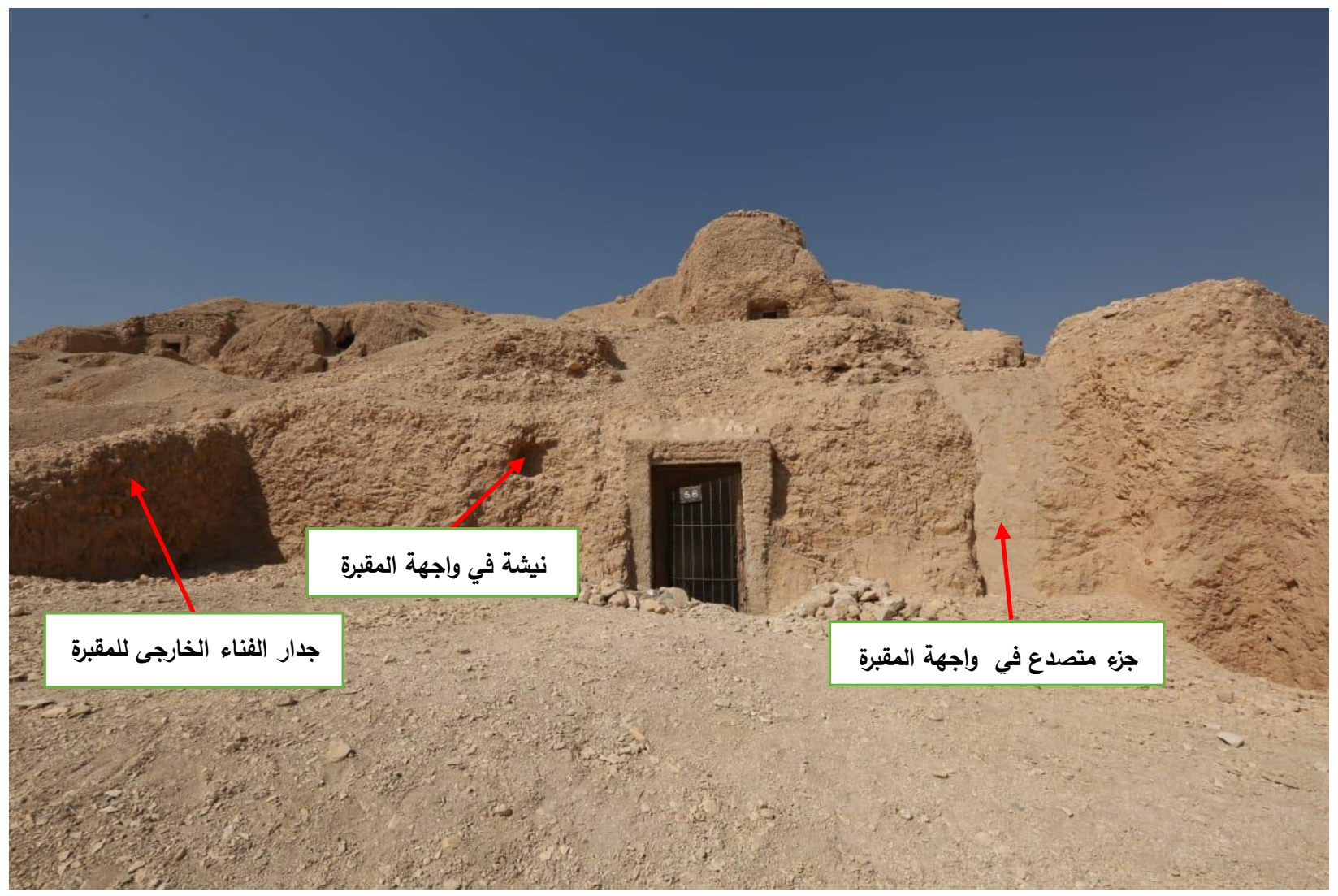

شكل رقم 2: واجهة المقبرة والفناء الخاص بها 


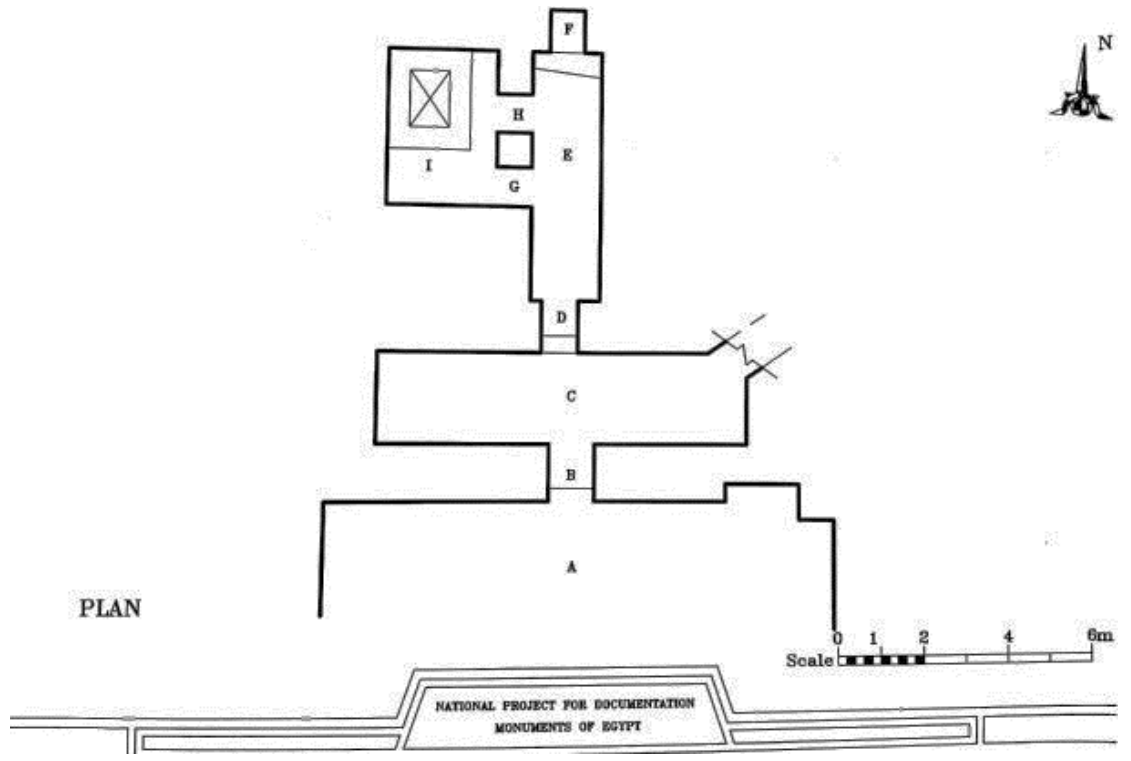

شكل رقم 3: تخطيط المقبرة

HALL : C

$1,8,9,16: 18$

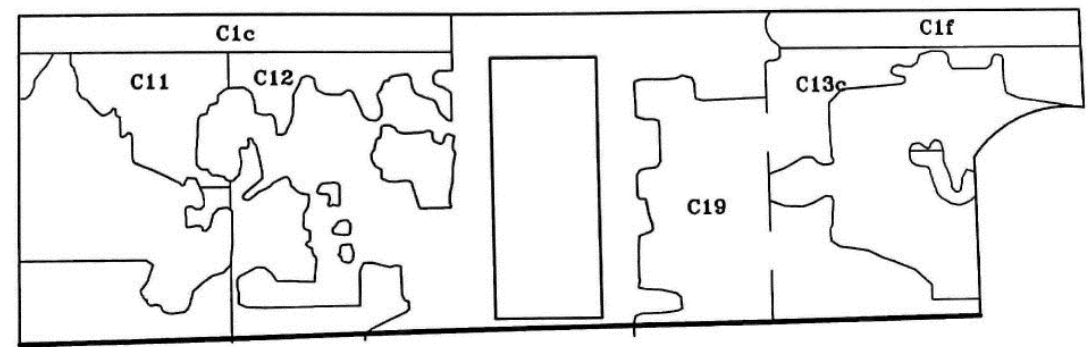

NORTH WALL

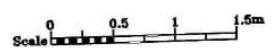

شكل رقم 4: يوضح الأجراء الباقية ليناظر الجدار الثمالى بالصالة العرضية 